\title{
GROWTH-RELATED CHANGES IN THE RECEPTIVE FIELD PROPERTIES OF RETINAL GANGLION CELLS IN GOLDFISH
}

\author{
ALAN MaCY* \\ Neuroscience Program, and Division of Biological Sciences, University of Michigan. \\ 830 N. University Avenue, Ann Arbor, MI 48109, U.S.A.
}

(Receited 4 December 1980)

\begin{abstract}
Intraocular recordings were made from retinal ganglion cells of small ( $<40 \mathrm{~mm}$ ) and large ( $>140 \mathrm{~mm}$ ) intact, submerged goldfish while stimuli were presented on a tangent screen. Very few cells recorded in either small or large fish responded selectively to direction of stimulus movement, suggesting that this property is first processed more centrally. Color and spatial opponent cells were encountered with the same frequency, respectively, in small and large animals, but orientation units were encountered much more frequently in large fish. If not caused by electrode sampling bias, this supports the idea that the density of amacrine cell synapses is positively correlated with receptive field complexity.
\end{abstract}

\section{INTRODUCTION}

The four different electrophysiological preparations which have been developed for the study of the goldfish's retinal ganglion cells each carry with them one or more disadvantages. Although the isolated retina (Wagner et al., 1960; Daw, 1968) confers advantages such as mechanical stability and optical accessibility, it is probably damaged during its removal from the pigmented epithelium. (Pinto and Pak, 1974a, 1974b), and the receptive fields observed are strongly affected by variables such as the amount of carbon dioxide in the superfusing gas mixture (Abramov and Levine, 1972), and the lighting conditions during dissection (Shefner and Levine, 1979). The in situ eyecup (Adams, 1970) deviates less from the state of the normal eye. Although the lens and cornea are removed, the retina remains normally circulated and in its normal position, adjacent to the pigmented epithelium. The optics of this preparation are uncertain, however. as the retinal image must be cast by external lenses through an exposed vitreous which frequently becomes cloudy. The intact optic nerve preparation (Jacobson and Gaze, 1964) avoids this problem, in that the normal dioptric apparatus forms the retinal image, but it carries the disadvantage that the experimenter cannot pick the region of the visual field to be probed (Gaze, 1970; Daw and Beauchamp, 1972). This problem does not exist in the optic tectum preparation (Jacobson and Gaze, 1964; Cronly-Dillon, 1964), but it is uncertain whether the units recorded are terminais of retinal ganglion cells or intrinsic tectal cells. Although commonly assumed to be the

* Address for correspondence: Dr Alan Macy, School of Optometry, University of California, Berkeley, 360 Minor Hall. Berkeley, CA 94720 . U.S.A. former, experiments aimed at demonstrating this, using the methods of Vanegas et al. (1973), gave equivocal results (Macy, unpublished).

The types of receptive fields encountered in the above investigations depended somewhat upon which preparation was used. Concentrically organized fields with spectral and/or spatial opponency have been seen in all of the preparations. In contrast, directionally selective units are common in the tectum (CronlyDillon, 1964: Jacobson and Gaze, 1964; Sutterlin and Prosser, 1970; Wartzock and Marks, 1973; Riemslag and Schellart, 1978), but have been observed only rarely in the optic nerve (Daw and Beauchamp, 1972; Riemslag and Schellart. 1978), and never in the isolated retina. Orientation selective units have been seen, but very infrequently, in the optic nerve (Daw and Beauchamp, 1972: Riemslag and Schellart. 1978).

This paper has three parts. First, I describe a new preparation which has none of the aforementioned problems. Second, I report some observations on the receptive field properties of the cells encountered in this preparation, and compare these findings with earlier ones. Finally, I compare the receptive fields of the retinal ganglion cells of small and large animals in order to learn how they changed as the animal grows. The retina of the fish is unusual, relative to those of other vertebrates, in that it grows throughout much of the animal's life. This growth reflects both a stretching of the preexisting retina, and an addition of new neurons (Müller, 1952; Johns and Easter, 1977; Johns, 1977). By comparing results from fish differing only in size, being of the same strain and obtained from the same source, one can assess the effects of growth (Johns and Easter, 1977).

In the second paper of this series (Macy and Easter, 1981) the same preparation is used to evaluate the 
growth-related changes in the sizes of these receptive fields.

\section{METHODS}

Goldfish (Carassius auratus, common strain) were acquired from Grassyforks Fisheries (Martinsville. Indiana). Two classes were used, with standard lengths of $35-45 \mathrm{~mm}$ and $135-140 \mathrm{~mm}$. These correspond to fish of ages less than $1 \mathrm{yr}$ and $4-5 \mathrm{yr}$. respectively (Johns and Easter. 1977. and unpublished data).

At the start of each experiment. a fish was placed in the anesthetic solution (tricaine methanesulfonate) until it stopped breathing, usually after $\$-10 \mathrm{~min}$. It was then injected intramuscularly with gallamine triethiodide (Flaxedil. $20 \mathrm{mg} / \mathrm{cc}: 0.025 \mathrm{cc}$, small fish: $0.3 \mathrm{cc}$, large fish). Control fish revived in $10-15 \mathrm{~min}$ if no Flaxedil was administered. A small triangular hole, approx. $0.5-1 \mathrm{~mm}$ on a side, was cut in the dorsal caudal sclera of the right eye. This was completed in 3-7 min. before the anesthetic wore off. The vitreous of the goldfish is quite viscous, and none was seen to leak out of the opening. Photographs of the eye taken before. and hours after, the surgery supported this observation by showing no change in the shape of the cornea. The fish was next submerged in a clear waterfilled plastic chamber and gently held between sponges. A tube led aerated water through the mouth and over the gills at a rate of $90-120 \mathrm{ml} / \mathrm{min}$ (small fish) or $150-200 \mathrm{ml} / \mathrm{min}$ (large fish). The animal's right eye gazed out through the water and through a flat clear plastic window at a tangent rear projection screen (Day-tex. Warsaw. Indiana) onto which the stimuli were projected from a dual-beam optical stimulator. The screen lay at an optical distance of $28.6 \mathrm{~cm}$ from the fish's eye. so that at the center of the screen, directly in front of the chamber, $1 \mathrm{~cm}$ on the screen subtended 2 deg of visual arc. At positions away from the center the subtense was lower due to refraction at the window of the chamber and the increasing distance to the tangent screen. Thus at $5 \mathrm{~cm}$ from the center. $1 \mathrm{~cm}$ subtended approx. $1.9 \mathrm{deg}$ and at $15 \mathrm{~cm}$. subtended $1.3 \mathrm{deg}$ of visual arc.

Metal-filled glass micropipettes (tip dia 6-8 $\mu \mathrm{m}$ ) were used (Dowben and Rose, 1953). Their signals were amplified conventionally and displayed on a storage oscilloscope and loud speaker. The electrode was advanced into the eye through the scleral hole. Once within the eye, the electrode was no longer under visual control. but contact with the retina was evident from the commencement of multi-unit activity. The electrode's position in the retina was checked histologically in a few cases after making electrolytic lesions. and was in the inner retina. close to the ganglion cell layer. The position of the optic disk was located by shining a light on the fish's translucent skull and determining the location in the visual field at which the pupil was luminous (Easter et al. 1977). This procedure. reproduceable to within about 3 of visual angle. allowed the position of the projec- tion of the optic disk to be marked on the screen, and was repeated after each examination of a receptive field. The disk projects in the dorsonasal quadrant of the visual field, approx. $15 \mathrm{deg}$ of visual angle from the center on a spoke displaced about $22 \mathrm{deg}$ from the vertical axis of the eye (Easter et al., 1977). This information was used to estimate the position of the center of each receptive field with respect to the optical center of the eye. It was assumed that the vertical axis of the eye was parallel to the true vertical, and therefore to the vertical axis of the screen. Even if this assumption were off by $20 \mathrm{deg}$. the distance of a receptive field from optic center would be miscalculated by less than 5 deg of visual angle.

Sampling was restricted to the central $60^{\circ}$ of the retina in all experiments. Since all new retinal neurons are added at the periphery (Johns. 1977). recording in the central retina assured that the cells sampled in the two size classes would be homologous. Thus, the results of these experiments may be interpreted as growth-related changes in receptive fields of the same population of cells.

At the end of each experiment. the right eye was removed and the lens diameter measured, for computation of the retinal magnification factor (Easter et al.. 1977).

Stimuli were either red (quartz-halogen source. Kodak Wratten 29 filter) or green (Wratten 58 filter). The spectral energy of the beam ("white", and with each of the Wratten filters) was measured with a calibrated photodiode (PIN-10DF, United Detector Technology. Santa Monica. California), positioned at the plane of the fish's pupil. The measurements were made at 10 wavelengths, roughly equally spaced between 400 and $700 \mathrm{~nm}$. using calibrated interference filters (Monopass Series. Optics Technology, Palo Alto. California). A knowledge of the optics of the eye (Charman and Tucker. 1973: Easter et al. 1977) per. mitted calculation of the spectral quantal flux at the plane of the retina. assuming no absorption by the plastic wall, intervening water, and preretinal ocular media. Stimulus intensity was controlled by calibrated neutral density filters. In all experiments presented here. the intensity of the green background was $6.2 \times 10^{9}$ quanta $/ \mathrm{sec}-\mathrm{mm}^{2}$.

A "white", flashing $60 \mathrm{deg}$ dia stimulus was used to find and isolate single units, which were then tested as described below.

Directional selectivity was assessed by moving a small red circulat stimulus $(5.6 \mathrm{deg}$ dia) through the center of a cell's receptive field in the horizontal and vertical directions (velocities: $30-100 \mathrm{deg} / \mathrm{sec}$ ). The unit was considered directionally sensitive if the magnitude of its response. judged by ear, was related to the direction of movement of the stimulus.

Spectral opponency was assessed by comparing a unit's responses to red and green stimuli presented on backgrounds of the other color. Stimulus disks (5.6 deg dia) centered on the most sensitive region of the receptive field were used. Stimulus intensities 


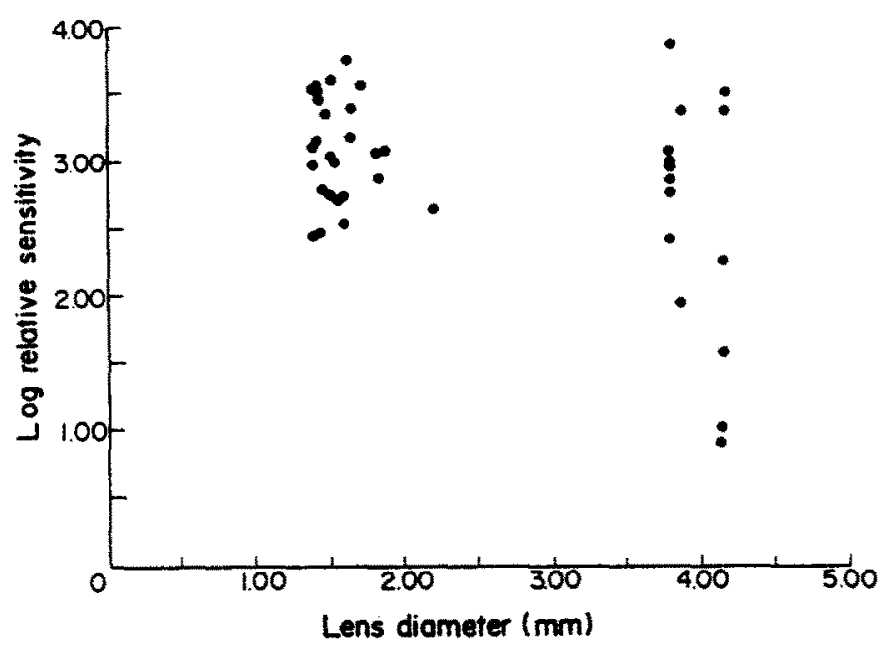

Fig. 1. Sensitivity as a function of lens diameter. Each point $(N=43)$ represents the measured sensitivity of a ganglion cell to a circular red stimulus with a diameter of 11.6 . presented on the same green background. Log relative sensitivity $=0$ corresponds to a retinal flux $(400-700 \mathrm{~nm})$ of $6.8 \times 10^{11}$ quanta $/ \mathrm{mm}^{2}-\mathrm{sec}$.

ranged up to $2 \log$ units above threshold. A cell was considered spectrally opponent if the red and green stimuli elicited threshold responses of opposite sign.

Units were tested for spatial opponency with central spots $\left(5.6^{\circ}\right.$ dia) and annuli $\left(17^{\circ}-24^{\circ}\right.$ i.d.) of the same color. All stimuli were presented on backgrounds of the other color. If small spots and annuli evoked responses of opposite sign, the cell was considered spatially opponent. However, cells which gave "on-off" responses to spot stimuli and "on" or "of" responses to annuli were not called spatially opponent, since non-spatially opponent cells could give responses of this type if stray light from the annular stimulation excited the central mechanism at threshold levels. For this reason the measured frequency of this class of units represents a lower limit of their true frequency.

Orientation selectivity was assessed with slit stimuli, $3^{\circ}$ wide and greater than $40^{\circ}$ long. which were either flashed on the receptive field or swept over it in a direction orthogonal to the long axis of the slit. The assessments were made on each cell isolated during the collection of the 55 cells from small fish and 51 cells from large fish studied in the companion paper.

The receptive fields of some cells were mapped with a red stimulus $\left(3^{\circ}\right.$ dia) on a green background. The sign of the cell's response: on, off, or on-of, was noted for each position within the receptive field.

Since units were often lost before the completion of testing (about $1 \mathrm{hr}$ ) not all of the tests were performed on each cell.

\section{RESULTS}

The preparation yielded well-isolated single units, typically $100-200 \mu \mathrm{V}$ amplitude on a noise level of $10-20 \mu \mathrm{V}$.
Figure 1 plots the log relative sensitivity of 43 units vs the lens diameter. In all cases, the same stimulus was used, a red disk $11.6 \mathrm{dia}, 1 \mathrm{sec}$ in duration, presented at $0.5 \mathrm{~Hz}$. The big fish are represented in the cluster on the right, the small ones, to the left. Although the mean $\log$ sensitivity was slightly less in the big fish, the difference is not statistically significant according to a two-tailed $t$-test $(P>0.05)$. Therefore all the thresholds may be pooled. The mean $\log$ threshold ( \pm SEM) was $8.9 \pm 0.1 \log$ quanta/sec $\mathrm{mm}^{2}$ at the retina. Using the assumptions of Powers and Easter (1978), this can be shown to correspond to receptor fluxes (in the large fish) of approx. 16,000 $636 \mathrm{~nm}$-equivalent quanta/red-sensitive cone sec, and $1600533 \mathrm{~nm}$-equivalent quanta/green-sensitive cone sec. The former number is $6.5 \mathrm{log}$ units above the dark adapted threshold, measured behaviorally, for a $636 \mathrm{~nm}$ disk with a diameter of 132 (Powers and Easter, 1978). The threshold is higher because a background is used here and because the stimulus is smaller. The effect of the decreased size can be estimated. If, in the behavioral study, spatial summation was governed by Ricco's law for stimuli up to $30^{\circ}$ dia. with no summation above this size (as seen for

Table 1. Frequency of different receptive field properties in small and large fish

\begin{tabular}{lccc}
\hline & $\begin{array}{c}\text { Directional } \\
\text { selectivity }\end{array}$ & $\begin{array}{c}\text { Spectral } \\
\text { opponency opponency }\end{array}$ & $\begin{array}{c}\text { Spatial } \\
\text { oppon }\end{array}$ \\
\hline Small fish & & & \\
$N$ & 20 & 24 & 24 \\
No. Positive & 2 & 8 & 13 \\
$\%$ Positive & 10 & 33 & 54 \\
Large fish & 12 & 15 & 14 \\
$N$ No. Positive & 0 & 5 & 9 \\
$\%$ Positive & 0 & 33 & 64 \\
\hline
\end{tabular}




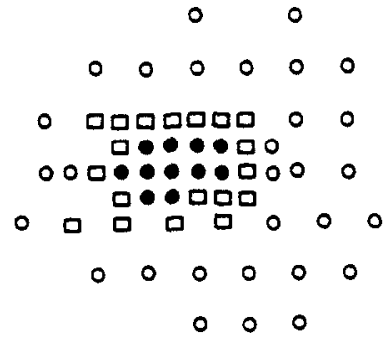

$000000-$ $-0000000$

$0000--0.00000000$

$-000-\bullet \bullet \bullet \bullet \circ 000-$

$-000-\bullet \bullet \bullet \bullet 0000-$

$000-0 \cdot 0 \cdot 000000$

$0--\bullet \bullet \bullet 000-$

$000 \bullet \bullet 0000$

$-000000-$

Fig. 2. Small spot maps of the receptive fields of two cells from a large fish (lens dia: $4.05 \mathrm{~mm}$ ). Maps were made with a red stimulus (dia: $3.0^{\circ} .2 .3 \times 10^{11}$ quanta $/ \mathrm{mm}^{2} \mathrm{sec}$ at the retina) on the green background. The symbols represent the positions at which the stimulus elicited on-responses (open circles), off-responses (filled circles), on-off-responses (open squares), or no response (dashes).

$533 \mathrm{~nm}$ stimuli: Northmore. 1977; Powers and Easter, 1978), the absolute threshold for an $11.6^{\circ}$ stimulus would be about $5.5 \mathrm{log}$ units below the thresholds typically measured in the present study. Therefore these experiments are in the photopic range of vision.
The results of the tests of directional selectivity, spectral opponency, and spatial opponency are shown in Table 1 . The table displays, for each receptive field property, the total number of cells tested and the number and percentage of those cells which displayed the property.

Of 32 units examined in small and large fish, only two showed any directional selectivity, and it was very weak. For example, as its strongest directional response, one of the units fired four spikes to a temporal to nasal movement, and three spikes to movement in the reverse direction. Both units were found in small fish, but the small sample size rules out any inference about differences between the two size classes.

The spectrally opponent units showed no unusual features. They were encountered slightly less frequently than in the isolated retina (Daw, 1968), but equally frequently in large and small fish.

Small spot maps from two of the spatially opponent units are shown in Fig. 2. Antagonistic responses from the surround region were evoked by small spots, in contrast to the case in isolated retina (Daw, 1968). The diameters of the surrounds in Fig. 2 exceeded $35^{\circ}$ or $2.9 \mathrm{~mm}$ on the retina. When stimulated with disks or annuli of dimensions predicted from the small spot maps, the responses conformed with expectation. For instance, the units shown in Fig. 2 gave off-responses to central disks, on-responses to annuli. Spatially opponent units were encountered with about the same frequency as in the isolated retina (Daw, 1968),

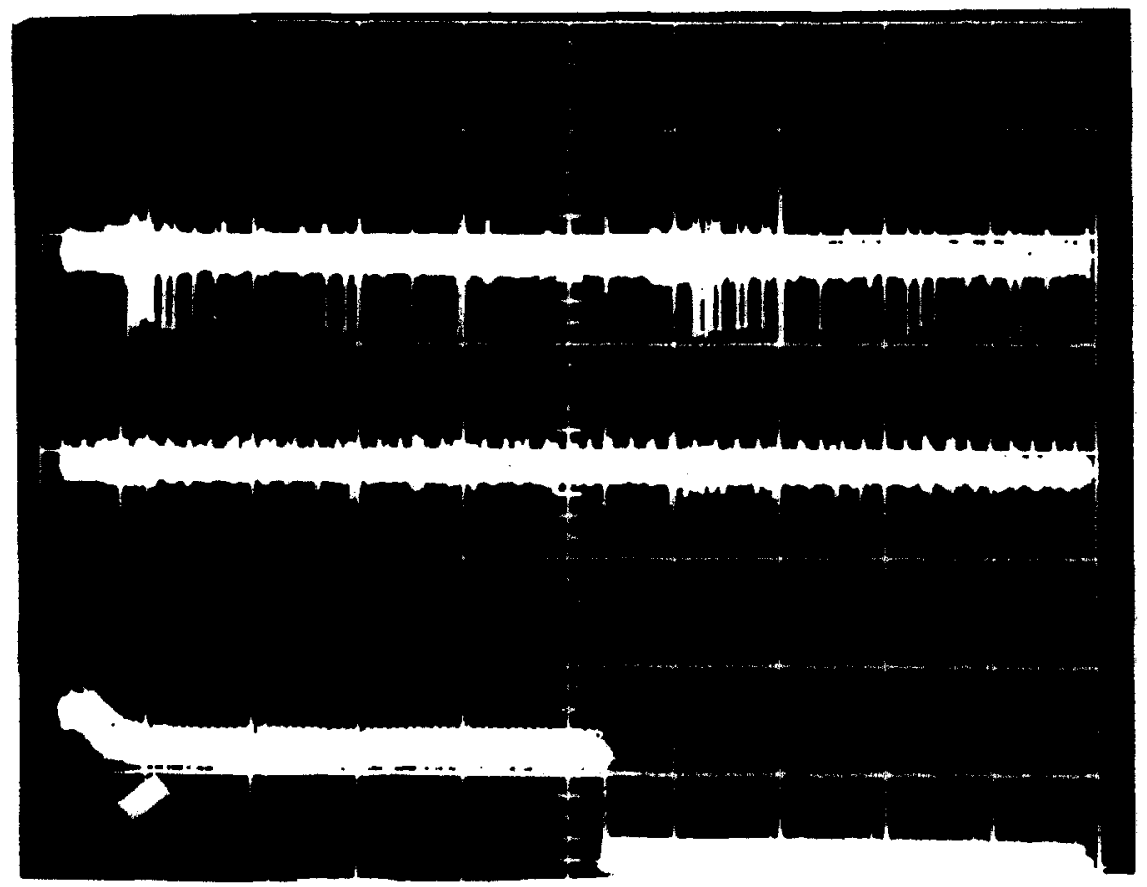

Fig. 3. Responses of an orientation-selective unit. The upper trace shows the response to a horizontal slit of light flashed on the receptive field for one second. The unit responds at the onset and the offset of the stimulus. The second trace displays the result of flashing a vertically oriented slit on the receptive field for one second. This stimulus did not elicit any response from the cell. The stimulus trace is shown at the bottom of the figure. Calibration: $0.2 \mathrm{sec}$ per large horizontal division, $50 \mu \mathrm{V}$ per large vertical division. 


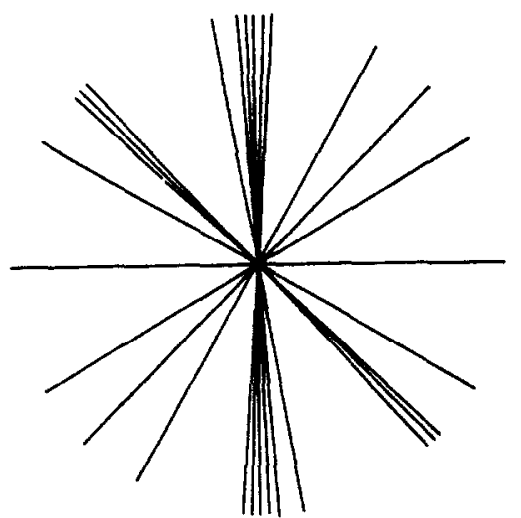

Fig. 4. Distribution of preferred orientations. Each line represents the preferred orientation for one orientationselective unit. When two or more units had the same preferred orientation, their lines were shifted $2 \%$ relative to one another for clarity of presentation.

and at nearly the same frequency in large and small fish.

An example of the response properties of an orientation-selective unit is shown in Fig. 3. When a horizontal slit of light was presented, the cell fired at both the onset and offset of the stimulus. The cell did not respond to a vertical slit presented anywhere. The response amplitudes of these orientation units, as judged by ear, decreased dramatically when the orientation of the stimulus differed from the preferred orientation by as little as $30^{\circ}$. Preferred orientations were approximately evenly distributed over $180^{\circ}$ as shown in Fig. 4. Although these units responded poorly to spots of light, rudimentary small spot maps were obtained from two orientation-selective units, and showed elongation of the receptive field at the expected orientation. These units responded poorly to changes in diffuse illumination, and therefore it is likely that many were missed in the initial isolation procedure. For this reason, it is probably not appropriate to compare the frequency of occurrence in this sample with those reported previously. Thirteen of the 14 orientation-selective units were encountered in large fish.

\section{DISCLSSION}

These results will be discussed with reference to two questions. First, to what extent do they modify previously held opinions about the receptive fields of the goldfish's retinal ganglion cells'? Second, what do they indicate about growth-related changes in these receptive fields?

\section{Receptice field organization}

Directionally selective cells were very rare. As was noted in the Introduction, this is consistent with earlier reports drawn from the optic nerve and quite different from reports based on tectal recordings. It seems reasonabie to conciude that the directionally selective tectal units recorded by others were intrinsic tectal cells, not retinal afferents, and that the tectum, not the retina, is the place at which directional information is abstracted from the visual image. This result could be explained by an electrode sampling bias only if the same biases were present in optic nerve and isolated retina preparations as well.

Although the measured frequencies of spectrally and spatially opponent receptive fields are roughly consistent with Daw's findings in the isolated retina. there is an important difference between Daw's results and the present ones. Many units (Fig. 2) had antagonistic surrounds that were demonstrable with small spot stimuli while Daw reported that surround responses were elicited only by annuli. He found that small spots evoked center-type responses regardless of their position. The discrepancy is probably due to the difference in preparation. Specifically, the procedure of isolating the retina could have damaged laterally conducting pathways, and thereby caused the excitation from a small stimulus in the surround to saturate at a level too low to excite the ganglion cell.

\section{Growth-related changes}

The only aspect of the receptive fields which depended upon the size of the animal was orientationselectivity. This growth-related increase in functional complexity correlates with some anatomical changes in the inner plexiform layer. Fisher and Easter (1979) showed that the number of synaptic contacts in the inner plexiform layer of the central retina is larger in big fish than in small. Presynaptic terminals in this layer are either "conventional," most of which originate from amacrine cells, or "ribbon-containing," from bipolar cells. The ratio: (number of conventional contacts/number of ribbon contacts) increased as well. Dowling (1968), Dubin (1970), and Fisher (1972) have reported that the relative number of conventional contacts is higher in retinas which have more complex receptive fields. The results reported here, coupled with the earlier anatomical study of Fisher and Easter (1979) support this view.

However, three possible complications must be considered.

First, if image quality were significantly poorer in small fish than in large, one might expect that equally prevalent orientation units would be less frequently detected in the small ones. However, experiments to be discussed in the second paper (Macy and Easter, 1980) showed that many cells recorded in small fish responded to drifting square-wave gratings with bar widths of $1.4 \%$, approximately half the width of the slit used to test units for orientation selectivity. Therefore the difference in the frequency of orientation units between small and large fish is not caused by poor image quality in the former.

Second, one might suggest that the orientation units were simply artifacts of an astigmatism of the fish's eye, and that this defect was more pronounced 
in large fish. This possibility may also be ruled out, however, since in each of three different fish. two units were seen which had preferred orientations differing from each other by more than $75 \mathrm{deg}$.

Third, the measured increase in the frequency of orientation units, during growth, could have been caused by an electrode sampling bias in favor of large cells (Humphrey. 1979). If it were assumed that orientation units have small cell bodies which increase in size during growth. they might have been present but undetected in the small retinas. In large fish the cell bodies would be bigger, and would have been detected more frequently by the electrodes. Thus an increase in their frequency would have been observed even though they were equally common in the retinas of small and large fish. This possibility cannot be excluded.

Acknowledgement:-This work was supported by PHS grant EY-00168 to S. S. Easter Jr and by fellowships from PHS (Training Grant EY-07022) and The Rackham School of Graduate Studies. I thank-Drs S. S. Easter Jr, D. G. Green and M. Alpern for useful discussions.

\section{REFERENCES}

Abramov I. and Levine M. W. (1972) The effects of carbon dioxide on the excised goldfish retina. Vision Res. 12 . $1881-95$

Adams T. (1970) Chromatic, spatial and temporal influences on single ganglion cell responses of the in rito goldfish retina. Ph.D. Thesis, Indiana University.

Charman W. N. and Tucker J. (1973) The optical system of the goldfish eye. Vision Res. 13,1-8.

Cronly-Dillon J. R. (1964) Units sensitive to direction of movement in the optic tectum of the goldfish. Nature 203. $214-15$.

Daw N. W. (1968) Colour-coded cells in the goldfish retina: extension of their receptive fields by means of new stimuli. J. Physiol. 197, 567-92.

Daw N. W. and Beauchamp R. P. (1972) Unusual units in the goldfish optic nerve. Vision Res. 12, 1849-56.

Dowben M. and Rose J. E. (1953) A metal filled microelectrode. Science 118, 22-24.

Dowling M. W. (1968) Synaptic organization of the frog retina: An electron microscopic analysis comparing the retinas of frogs and primates. Proc. Roy. Soc. B 170 , $205-28$.

Dubin M. W. (1970) The inner plexiform layer of the vertebrate retina: A quantitative and comparative electron microscopic analysis. J. comp. Neurol. 140, 479-506.

Easter S. S. Jr. Johns P. R. and Baumann L. R. (1977) Growth of the adult goldfish eye. 1: Optics. Vision Res. $17,469-77$.
Fisher L. J. (1972) Changes during maturation and metamorphosis in the synaptic organization of the tadpole retina inner plexiform layer. Nature 235, 391-393.

Fisher L. J. and Easter S. S. Jr (1979) Retinal synaptic arrays: Continuing development in the adult goldfish. $J$. comp. Neurol, 185, 373-380.

Gaze R. M. (1970) The Formation of Nerce Connections. Academic Press, New York.

Humphrey D. R. (1979) Extracellular single unit recording methods. In Electrophysiological Techniques, copyright: Society for Neuroscience. Bethesda.

Jacobson M. and Gaze R. M. (1964) Types of visual responses from single units in the optic nerve of the gold. fish. Q. Jl. exp. Physiol. 49, 199-209.

Johns P. R. (1977) Growth of the adult goldfish eye. III: Source of the new retinal cells. $J$. conp. Netrol. 176 , 343-58.

Johns P. R, and Easter S. S. Ir (1977) Growth of the adult goldfish eye. II: Increase in retinal cell number. $J$. comp. Neurol. 176, 331-42.

Macy A. and Easter S. S. Jr (1981) Growth-related changes in the size of receptive field centers of retinal ganglion cells in goldfish. Vision Res. 21, 000-000.

Muller H. (1952) Bau und Wachstum der Netzhaut des Guppy (Lebistes reticulatus). Zool. Jher. Neapel. 63. 275-324.

Northmore D. P. M. (1977) Spatial summation and light adaptation in the goldfish visual system. Nature 268. 450-1.

Pinto L. H. and Pak W. I. (1974a) Light-induced changes in photoreceptor membrane resistance and potential in Gecko retinas. I. Preparations treated to reduce lateral interactions. J. gen. Phisiol, 64, 26-48.

Pinto L. H. and Pak W. I. (1974b) Light-induced changes in photoreceptor membrrane resistance and potential in Gecko retinas. II: Preparations with active lateral interactions. J. gen. Physiol. 64, 49-69.

Powers M. K. and Easter S. S. It (1978) Absolute visual sensitivity of the goldfish. Vision Res. 18, 1137-47.

Riemslag F. C. C. and Schellart N. A. M. (1978) Evoked potentials and spike responses to moving stimuli in the optic tectum of goldfish. J. comp. Physiol. 128, 13-20.

Shefner J. M. and Levine M. W. (1979) Comparison of properties of goldfish retinal ganglion cells as a function of lighting conditions during dissection. Vision Res. 19, 83-9.

Sutterlin A. M. and Prosser C. L. (1970) Electrical properties of goldfish optic tectum. J. Neurophisiol. 33, 36-45.

Vanegas H., Amat J. and Essayag-Millan E. (1973) Electrophysiological evidence of tectal efferents to the eye. Brain Res. 54, 309-13.

Wagner H. G., MacNichol E. F. \& Wolbarsht M. L. (1960) The response properties of single ganglion cells in the goldfish retina. J. gen. Physiol. 43, 45-62.

Wartzock D. and Marks W. B. (1973) Directionally selective visual units recorded in the optic tectum of goldfish. J. Neurophysiol. 36, 588-604. 